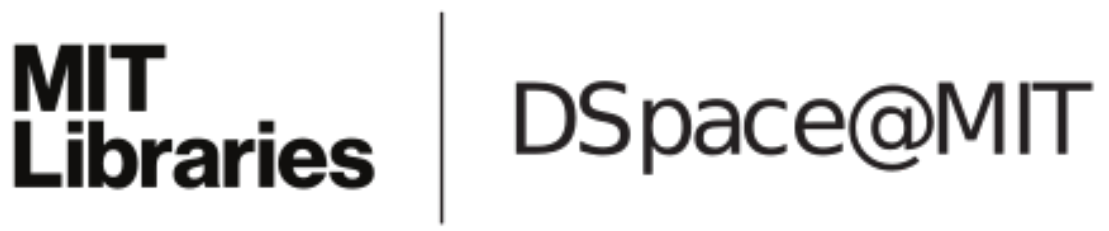

\author{
MIT Open Access Articles
}

\section{UbiqBio: Adoptions and Outcomes of Mobile Biology Games in the Ecology of School}

The MIT Faculty has made this article openly available. Please share how this access benefits you. Your story matters.

Citation: Perry, Judy, and Eric Klopfer. "UbiqBio: Adoptions and Outcomes of Mobile Biology Games in the Ecology of School." Computers in the Schools 31, no. 1-2 (April 3, 2014): 43-64.

As Published: http://dx.doi.org/10.1080/07380569.2014.879771

Publisher: Taylor \& Francis

Persistent URL: http://hdl.handle.net/1721.1/91568

Version: Author's final manuscript: final author's manuscript post peer review, without publisher's formatting or copy editing

Terms of use: Creative Commons Attribution-Noncommercial-Share Alike 
UbiqBio: Adoptions and Outcomes of Mobile Biology Games in the Ecology of School

Judy Perry, Ed.M., Research Manager, MIT Scheller Teacher Education Program Eric Klopfer, Ph.D., Professor and the Director of the MIT Scheller Teacher Education Program Massachusetts Institute of Technology

\begin{abstract}
Author Note
This research was supported by National Institutes of Health Grant 1RC1MH088912-01 awarded to Eric Klopfer.
\end{abstract}

Correspondence concerning this article should be addressed to Judy Perry, Scheller Teacher Education Program, Massachusetts Institute of Technology, E15-301, 20 Ames Street, Cambridge, MA 02421. Email: jperry@ mit.edu. Phone: +1 (617) 452-4977. 


\begin{abstract}
The integration of learning games into schools holds significant promise, yet faces numerous obstacles. Ubiquitous games (casual games for smart phones) attempt to motivate students to engage repeatedly with content beyond school, while enabling teachers to facilitate deeper reflection on game-related curricula during class. During a two-year study, researchers developed four biology-themed UbiqGames and curricula. An analysis of gameplay patterns and post-test data suggests that both male and female students played the games. Areas where content knowledge gains correlate with specific game design attributes (e.g., simulation feedback and depth of content) suggest areas for further research on 'casual' learning games.
\end{abstract}

Keywords: mobile, smart phone, casual game(s), games, simulation, biology, science 
UbiqBio: Adoptions and Outcomes of Mobile Biology Games in the Ecology of School Over the past decade, games have become an increasingly popular activity for today's youth, nearly all of whom - both boys (99\%) and girls (94\%) - play computer-based games as a free-choice activity (Lenhart, 2008). Video game usage among youth 8-18 years old has increased from an average of 26 minutes per day in 1999, to 49 minutes per day in 2004, to 1:13 in 2009 (Rideout, Foehr, \& Roberts, 2010). During the same time period, a growing body of research has demonstrated that beyond their mere entertainment value, games can support powerful learning experiences (Groff, Howells, \& Cranmer, 2012; Klopfer, 2008) in which players acquire agency and test theories (Gee, 2003), practice skills and take on novel identities (Shaffer, Squire, Halverson, \& Gee, 2005), and engage in meaningful discourse (Steinkuehler, 2006). Research also suggests that the affordances of games may be especially promising within the domain of science education, helping learners move beyond rote memorization toward deeper understanding (Clark, Nelson, Sengupta, \& D’Angelo, 2009).

During the past three decades, educators seeking to leverage the potential benefits of learning games have employed a range of computer game genres including simulations, roleplaying, strategy, sports, puzzle, and action games (Squire \& Barab, 2004; Sandford, Ulicsak, Facer, \& Rudd, 2006; Dondlinger, 2007). The simulation genre in particular can be a powerful tool in which users explore outcomes based on manipulating the parameters within a model (Thiagarajan, 1999), allowing them to control otherwise unalterable variables (Squire, 2003) or observe behavior over time (Herz, 1997). Simulations comprise many of the most widely adopted, iconic educational computer games: Lemonade Stand (1973), Oregon Trail (1985), Odell Lake (1986), and SimCity (1989). 
Despite the potential benefits of digital-game based learning, the typical "ecology" of today's schools (defined as the physical space, culture, and duration of the formal school day) often poses significant barriers to the frequent and recurring use of technology (Groff \& Mousa, 2008), including computer games and simulations, in its classrooms (Kebritchi, 2010). Baek (2008) identifies six factors affecting teachers' adoption of computer games in the classroom: inflexible curricula, negative effects of gaming, student lack of readiness, lack of supporting materials, fixed class schedules, and limited budgets. While Baek's data originates from Korea, many themes resonate within the U.S. and elsewhere. The culture of computer games, so ubiquitous to students and yet so foreign among typical schools, has prompted some educators who wish to leverage the perceived pedagogical benefits of games within a formal educational space to completely reimagine schools that wholly embody game-based principals (Salen, 2007). However, for the vast majority of schools, change will come incrementally, in so-called evolution rather than revolution. Given these constraints, the authors of this paper asked: Could $a$ suite of content-based games, when deliberately designed to fit within the existing school ecology, gain adoption and improve learning outcomes? If so, what game design characteristics correlate most closely with learning and engagement?

\section{Mobile, Casual Games}

Casual games have gained tremendous popularity in recent years (Juul, 2009). These casual games circumvent some of the barriers which more hard-core games present to novice players: they are easy to learn, requiring less initial investment and generally less experience and skill, and are intended to be played in shorter bursts of time, enabling players to play without committing significant amounts of time in any one "sitting." Casual games' attributes have 
enabled play among entirely new audiences and settings (Juul, 2009). However, to date there is relatively little research about the design and efficacy of casual learning games.

To best leverage the pedagogical advantages of the iterative nature of casual games, the materials themselves must be readily accessible to students. Yet students do not all have reliable access to traditional computers on a regular basis. With the growing ubiquity of mobile computers and smart phones, these devices may offer a potential form of access to a wider population. Data from a 2012 report from The Pew Internet and American Life Project (Lenhart, 2012) states that $31 \%$ of teens (ages 14-17) already own and use smart phones, and this number is growing rapidly. As smart phones proliferate among students from a wider range of SES levels, schools' official attitudes about student possession of mobile devices shifts from derision (e.g., banning students' smart phones from schools) to necessity (e.g., requiring smart phones as standard learning equipment), students will spend much of their day toting their own powerful computing devices accessible anytime, anywhere.

\section{Prior UbiqGames: Palmagotchi \& Weatherlings}

Preliminary pilot projects undertaken by this lab sought to examine the feasibility of a new approach to utilizing learning games, called Ubiquitous Games (or UbiqGames for short). The goals were two-fold: (1) to develop a pedagogical/practical model which leveraged gamebased learning that fit within the ecology of school, and (2) to make games that both engaged students and supported learning. To overcome potential barriers to adoption (Baek, 2008), UbiqGames sought to utilize both a technological and pedagogical approach that fit within the school ecology (Table 1). To achieve this, UbiqGames consist of content-rich games, played by students primarily on mobile devices outside of class time. By shifting the lion's share of gameplay outside of the classroom, and utilizing class time for reflection and discussion, the goal 
was to carefully craft learning materials which not only made adoption possible, but also are consistent with what is known regarding effective pedagogy.

Across these pilot projects, researchers asked: Would students find time and motivation to play games on mobile devices outside of class time? Would teachers be able to integrate students' gameplay experiences directly into productive classroom activities? Our first attempts focused on piloting the design of a mobile, casual learning game. In Palmagotchi (2004), students cared for virtual birds that "lived" on their mobile computer. Students observed their own birds' traits over time in the context of selection pressures, then compared them collectively across their entire class, referencing Darwin's seminal observations of the finches in the Galapagos. Findings from this pilot (Klopfer, 2008) demonstrated that students were motivated to play on their own time, engaged in discussion with their peers, and used class time for productive discussion and synthesis. However, Palmagotchi provided no opportunity for teachers to digitally monitor their students' in-game performance. Players also had to manually aggregate their game data, which while a worthwhile skill, was not the focus and took time away from the deeper analysis of the data itself. In the second UbiqGame Weatherlings (2009), students played a Pokemon-style card dueling game requiring strategic decisions based on consideration of realistic weather and climate data. Again, the Weatherlings pilot suggested that the UbiqGames model was feasible. However, neither project yet sought to investigate outcomes based on implementation of a suite of related, but distinct games nor on assessment of learning outcomes. While the UbiqGames strategy is not unique, and others have sought to capitalize on similar affordances (see Klopfer, Sheldon, Perry, \& Chen, 2012 for a review of that work), controlled studies connecting gameplay and game design with learning outcomes are not yet well documented within this space. 
More broadly, at this point there is good theoretical and anecdotal evidence on the potential of learning science through games (Clark et al., 2009; Honey \& Hilton, 2011), but the specific evidence is still sparse. One issue is that in order to produce knowledge that is useful for both practitioners adopting games and designers creating games, research must inform the specific characteristics employed in games. Thus, the next step in our research has been to test games of different designs in controlled classroom trials in order to begin to identify some of these characteristics that might be useful for both practitioners and designers. While we do not isolate individual game characteristics in each of the games, we do provide variation in design that can be used to correlate with outcomes and suggest further areas for research.

\section{UbiqBio Study}

\section{Background}

The life sciences, taken as a whole, contain several foundational yet challenging topics that cannot be fully addressed through direct observation or hands-on exploration. Genetics, for example, is an excellent topic for computer simulation since it relies upon iterating over multiple generations, observing probabilistic outcomes, and seeing linkages between genotype and phenotype, concepts which are difficult if not impossible to recreate under the constraints of a typical high school biology class, and there is a rich history of these simulations (e.g. Hickey, Kindfield, Horwitz, \& Christie, 2003; Buckley, Gobert, Horwitz, \& Dwyer, 2010). The challenge for educators is to provide participatory, hands-on experiences that offer students insights into these complex, hard-to-teach topics. Given prior outcomes in which UbiqGames developed for other science-themed topics were adopted by teachers and students, questions emerged around how best to employ a suite of mobile educational games developed to motivate students to engage with and reflect upon various topics in biology. For the UbiqBio project specifically, 
researchers asked: Would students who played UbiqBio games demonstrate measurable improvements to learning outcomes compared to a control group? And given the challenges inherent in creating effective learning games (that fit within the school ecology, are highly engaging, and improve learning outcomes), which game design characteristics emerged among the most 'effective' games?

\section{UbiqBio Games and Game Design}

These questions were among those asked as part of a two-year study funded by NIH (award \# 1RC1MH088912-01). The UbiqBio project sought to assess the potential of this new UbiqGames genre of educational tools applied to the domain of introductory biology (for additional discussion, see Perry \& Rosenheck, 2012; Rosenheck, 2012).

Designing effective learning games is not easy. To meet the needs of students, welldesigned learning games ideally immerse players in a context in which they can take actions relevant to the content domain and see outcomes, prompting them to develop an understanding of the underlying concept or system. Seeking to create UbiqBio games that motivate student engagement, we utilized many established design principles and game mechanics (Malone, 1981). Malone's design heuristics relating to challenge were particularly relevant, including the emphasis on presenting clear goals with performance feedback (to tell players if they are achieving their goals), and variable levels of difficulty (to provide appropriate levels of challenge). To varying degrees, each UbiqGame also sought to enable players to progress at their own pace through increasingly more challenging levels of gameplay, an approach used to situate the learner with his zone of proximal development (Vygotsky, 1978). This leveling is critical to sustaining engagement: If the level is too challenging, the game risks losing the player 
to frustration. Conversely, if the game is too easy, boredom ensues and the player is no longer challenged with 'hard fun' (Papert, 1988).

In addition to motivating learners through engaging gameplay and appropriate level of challenge, the casual-simulation-game genre promotes student interactions with the underlying system repeatedly over multiple sessions, over multiple days. This genre offers the potential for iterative learning integration over time (Linn, 2005/2012) rather than a one-and-done approach. Leveled gameplay coupled with facilitated reflection attempts to scaffold students as they ascend to higher levels of gameplay, developing mastery of a subject through a form of deliberate practice (Ericsson, Krampe, \& Tesch-Römer, 1993) in which the student revisits the task, refining her approach, knowledge and technique through mindful reflection. In contrast with traditional paper-and-pencil homework, interactive games and simulations, when used as supplemental materials, offer players appropriate increasing levels of challenge, feedback and opportunities to return and achieve mastery. Although the games are designed as single player experiences, the games and curriculum are designed with the larger classroom context in mind, in which students' gameplay experiences become a springboard for broader discussion and reflection. Piggybacking on their students' gameplay experiences, teachers assume the role of facilitator, guiding class discussion to reflect on their strategies and stumbling points. This approach mirrors conceptual shifts embodied within the Next Generation Science Standards (2013) that encourage teachers to focus on core ideas. By encouraging students to unpack the experiences of gameplay into broader concepts, teachers move students beyond isolated facts towards organizational structures for acquiring new knowledge. This approach shares some attributes with the "flipped classroom" model (Baker, 2000) - a blended approach utilizing Internet-based instruction (e.g., video lecture) followed by facilitated classroom exploration and 
discussion. However, rather than merely watch a canned lecture prior to class, students alternatively play domain-specific games whose content, vocabulary and strategies would prime students, giving them a common informal experience prior to formal classroom time. Teachers would then structure classroom activities to draw upon students' gameplay experiences, encouraging comparisons of strategies, successes and challenges.

From the start, UbiqBio games were designed in collaboration with experienced biology teachers who served as teacher consultants throughout the design process. In this capacity, the collaborating teachers: (1) helped us determine the four content areas covered by the games (selected because teachers agreed they were hard to teach and mapped well to simulation game dynamics), (2) provided feedback on game designs, and (3) created related classroom curricular materials linking gameplay with classroom instruction (worksheets, discussion topics, etc.).

Four different UbiqBio games (Table 2) and related curriculum were designed and utilized in this study. While all four games shared a similar approach, each game also was unique in terms of its domain-specific content, underlying simulation, level of simulation feedback, content depth, narrative realism, variable difficulty, type of knowledge, and performance feedback. The domain-specific content specifies the biology concepts central to the gameplay itself. The underlying simulation is the specific model representing these concepts. Closely related to this is the game's level of simulation feedback, the degree to which the game represents, visually or otherwise, information based on interactions with the underlying model. The content depth describes the degree to which the game introduces new and increasingly complex ideas. Narrative realism refers to the degree to which the simulated game world parallels real-world entities, experiences or knowledge. The variable difficulty of a game is the degree to which the game presents a variety of challenges increasing in complexity and/or 
difficulty. A distinction can also be made between different types of knowledge used as players continually solve problems within the games, either conceptual knowledge (used to understand an underlying concept or model) or procedural knowledge (used to perform a task). Performance feedback denotes the game's immediate feedback allowing the player to assess for herself how well she is doing. Images (Figure 1) and descriptions of the four games follow:

Beetle Breeders. Goal: Try to earn the most money by fulfilling customer requests (contracts) for specific beetles.

Gameplay: Players maintain their own exotic beetle pet shop and begin with a starter set of beetles and continue to breed until they produce beetles with the specific desired varieties. Since breeding costs money, the most successful players will be thoughtful about their breeding selections. Additional Punnett square challenges offer bonuses to students who accurately predict the potential outcomes of their breeding. As players advance through the game to more difficult levels, new patterns of inheritance emerge including sex-linked, co-dominant, and polygenetic traits.

- Simulation/Simulation Feedback: Uses accelerated time, allowing students to manipulate genetic crossings and observe their beetle offsprings' genotypes and phenotypes.

- Content Depth: A fairly broad range of related genetics content is included in the game, which is added sequentially as gameplay progresses.

- Narrative Realism: The traits of the beetles are fairly realistic. The genetic modeling is also realistic.

- Variable Difficulty: The game progresses through several levels of increasing difficulty. 
- Knowledge: Strategically breeding beetles requires significant conceptual knowledge of genetics concepts. A subsection of the game prompts players to complete Punnett squares, which requires some procedural knowledge.

- Performance Feedback: The value of a player's bank account generally correlates with success in the game. Players also receive feedback if they correctly or incorrectly complete each box within the Punnett squares.

Invasion of the Beasties. Goal: Identify the enemy's weakness and genetically engineer her own fighter's zygote whose strengths can overpower the enemy.

Gameplay: A horde of terrible "beasties" is attacking. Players must refer to the Universal Monster Genetic Code to select the optimal codons that specify which amino acids will be added to the protein strand to yield desired phenotypes. As players move through higher levels of gameplay, they proceed from the protein/amino acid level to the somewhat more nuanced level of specific nucleotides.

- Simulation/Simulation Feedback: Allows players to manipulate and see the effects of alterations to nucleotides and amino acids, emphasizing the link between these modifications and the resulting protein. A simplified version of the Universal Genetic Code is included. Special consideration was taken in designing the player interactions so that immediate feedback would show the potential (in)significance of changing a single nucleotide.

- Content Depth: A moderate amount of content (DNA translation and protein synthesis) is included in the game.

- Narrative Realism: The traits of the beasties are fantastical.

- Variable Difficulty: Three levels of gameplay allow players to progress in difficulty. 
- Knowledge: The topic itself is somewhat procedural, in that it requires players to reference the correct materials and them utilize them to create a sequence which generates the desired protein.

- Performance Feedback: Players see if they have defeated the enemy Beastie.

Island Hoppers. Goal: Earn the most points by altering the conditions of the island to make the bunny population meet specific goals.

Gameplay: Each player controls an isolated island populated by, among other things, a large number of bunnies. At any time, the player can view a histogram showing the distribution of the bunny population for any of nine bunny traits. The player can also control any of seven environmental conditions (e.g., temperature, number of predators, color of tree bark) on the island, some of which act as selection pressures that influence the likelihood that certain bunnies will survive to reproduce. By advancing ten generations at a time, players can watch as the distribution of traits among their bunny population potentially shifts at any given time. To help players know which island conditions to change, "fact cards" are available suggesting possible connections between environmental conditions and relative advantages of specific bunny phenotypes.

- Simulation/Simulation Feedback: Allows players to manipulate environmental factors to potentially create selection pressures. Uses accelerated time to show changes across multiple generations. Actions taken by the player yield significant feedback. Dynamic histograms provide immediate feedback if the relevant selection pressure is changed so as to alter the population over time.

- Content Depth: A moderate amount of content (evolution, selection pressures) is included in the game. 
- Narrative Realism: The traits of the bunnies and their response to selection pressures are fairly realistic.

- Variable Difficulty: Although two levels of difficulty require advanced players to achieve a finer granularity of precision, the essential game tasks remain unchanged.

- Knowledge: The topic itself is highly conceptual, meaning it requires understanding of how parents are more or less likely to survive and pass along their genotype to their offspring based on relevant selection pressures.

- Performance Feedback: Players see to what degree their histograms meet the criteria specified in their current goals.

Chomp!. Goal: Alien food webs have become unbalanced and the player's mission is to put them back in equilibrium.

Gameplay: In phase 1, players are given a goal of increasing or decreasing the population of a certain species and must make a change to a neighboring species to cause the desired effects in the food web. In phase 2, aliens are going around from planet to planet looking for things to snack on. In each round they visit a different alien ecosystem and "chomp" (thus completely removing) one of its species. The disappearance of one species has a direct, immediate effect on various other species. Looking at the recent changes in the food web, players must figure out which species got chomped, in order to save that species and restore balance to the food web.

- Simulation/Simulation Feedback: Allows players to modify food webs based on additions or reductions in the populations of various creatures. There is relatively little feedback regarding what is happening to populations beyond "increasing" "decreasing" or "unchanged". 
- Content Depth: A very focused amount of content (immediate effects of changes within a food web) is included in the game.

- Narrative Realism: While the food web diagrams are representative of those used in standard biology, the creatures (while representing producers and consumers) are very fantastical, removing players' ability to guess based on prior knowledge of earth's species.

- Variable Difficulty: Phase 1 missions require players to read food web diagrams, while missions in Phase 2 require a bit more interpretation. The progression of difficulty is relatively flat.

- Knowledge: The topic itself is procedural, meaning it requires reading the diagram and interpreting the visualization.

- Performance Feedback: Player score increments with correct answers. Otherwise, feedback in minimal. Players do not receive meaningful wrong answer feedback. As mentioned previously, game characteristics are not uniquely isolated, which the designers felt would have made for a contrived set of games. Instead, variation is provided that allows us to correlate outcomes with dynamics. This methodology allows us to better understand the contributions of particular characteristics, and connect that understanding across studies, without relying on contrived games that are merely research instruments.

\section{Methods}

\section{Sample}

A total of 239 students ( $n=108$ male; $n=99$ female, $n=32$ no response) participated in the study. Participants were $9^{\text {th }}$ or $10^{\text {th }}$ graders in one of seven teachers' classes across four Boston-area high schools. All four schools were in urban, low SES districts. 
The experimental group consisted of 156 students taught by six teachers across three schools. All students were enrolled in standard introductory biology classes. Teachers implemented all four UbiqGames in each participating class, although due to absences and other factors, not all students played all four games.

The control group $(n=83)$ consisted of a separate, equivalent population of introductory biology students. To minimize potential teacher effect, the control group consisted of students in the same teachers' classes one year prior to the experimental study (with one exception where a school representing similar demographics/SES was substituted during the experimental portion of the study). Control group students did not play the UbiqBio games, but completed identical content assessment and surveys at the same point in the school year one year prior to the experimental students.

\section{Implementation}

While UbiqGames were designed assuming a future scenario in which schools ultimately would either employ a BYOD (bring your own device) approach or loan mobile devices to some or all students, the majority of students participating in the study were from low-middle SES groups. Only a small number of students possessed their own smart phones capable of accessing the games. Therefore, in the interests of equity and uniformity, the researchers felt that it was necessary to provide smart phones so as not to skew the sample. Teachers utilizing the UbiqBio games and curriculum were therefore loaned classroom sets of smart phones (HTC Incredibles running Android OS). Phones provided by the researchers had working data plans (but no voice plan) allowing students to use the phone's web browser. Students could therefore access the games anywhere they could get a $3 \mathrm{G}$ or Wi-Fi signal, which was nearly ubiquitous for all 
students. Students borrowed the phones, taking them home for the duration of each of the four units.

Teachers attended monthly professional development workshops where they received training on how to play and incorporate the games into their curriculum. Suggestions were made regarding the introduction of the game, but as researchers were interested in whether or not the games could fit into the ecology of the classroom and teachers were allowed to modify the implementation as they saw fit, allowing students to play as much or as little as they liked. Implementations of each game typically lasted between one and two weeks. Table 3 provides a sample curriculum, in this case for Invasion of the Beasties, showing a model of teacher implementation. Some of the teachers offered small amounts of credit in various forms for playing the games. The order in which games were integrated also varied by teacher, depending on their school curriculum.

\section{Data Collection}

All control and experimental students completed a written survey, providing basic demographic data. All students also completed a written content assessment covering biology content questions relevant to each of the four UbiqBio games. Test items were drawn from prior years' MCAS (Massachusetts Comprehensive Assessment System) questions (seven genetics questions, five evolution questions, two translation questions and two food webs questions, roughly representing the weighing of each topic's presence on the state exam). In addition, a centralized server automatically logged student game data capturing time on task, number of logins, highest level completed and other relevant data. Each student's log data was paired with his or her assessment and survey data.

\section{Findings and Discussion}


Log data recorded the number of minutes students played each UbiqBio game (Fig 2). On average, students spent significantly more time (roughly four hours per student) playing Beetle Breeders (genetics) compared to the other three games. Even for the least played game, Chomp!, students averaged over an hour of total game play.

Game play did vary by gender. While many of the teachers expected males to play more, it was the females who played more often (Fig 3). This difference was statistically significant in Chomp! (mean= 99 minutes for females vs. 49 minutes for males, $\mathrm{p}=.034)$, while it was not for Beetle Breeders $($ mean $=318$ minutes for females vs. 235 minutes for males, $\mathrm{p}=.081$ ). Despite teachers' predictions to the contrary, two factors corroborate these results. First, researchers have demonstrated that female students report more positive attitudes toward biology (Weinburgh \& Englehard, 2010). Second, data analyzing patterns of video game usage (Rideout, Foehr, \& Roberts, 2010) show that males (8-18) typically play video games for 1:37 hours per day, compared with females (8-18) (49 minutes per day). However, when measuring time spent playing games specifically on cell phones, Rideout et al. (2010) demonstrate far less of a distinction between males (17 minutes per day) and females (16 minutes per day). Given that UbiqBio games were both biology themed and played on mobile devices, female students may have found them more appealing than games on other topics played on other platforms.

Differences between genders were also seen in overall test scores (Fig 4). For all analyses we have discarded outliers where students scored four or fewer correct answers on the test, which consisted of 26 multiple-choice (four choices) questions (a subset $(n=16)$ of which were directly related to content included within the UbiqBio games). Graphical analyses of the class distribution indicated that a small number of students in each class did not take the test seriously, and so these outliers are ignored for both control and experimental groups. Test scores (scaled to 
provide comparison across sub-sections), pooled across experimental and control, show that females in general score higher on each of the subsections, with females scoring significantly higher in genetics (mean $=4.87$ for females vs. 3.99 for males, $\mathrm{p}<.01$ for 2 -tailed $\mathrm{T}$-test) though not statistically significantly higher in translation (mean= 1.80 for females versus 1.55 for males, $\mathrm{p}=.055)$ and evolution (mean= 3.85 for females and 3.39 for males, $\mathrm{p}=.088$ ).

The design of each of the four games differed substantially (see Table 2), as did the adoption by players. As Figure 5 illustrates, only Beetle Breeders (genetics, mean= 4.61 for experimental group and 4.11 for control, $\mathrm{p}=.0472$ for 2-tailed T-test) yielded statistically significant differences when compared to the control group. This is likely due to a combination of the game's depth of content (which also allowed us to include content assessment questions on a broader range of subtopics) and increasing level of challenge, which in turn engaged students for much longer duration of gameplay. Gender did not influence the difference between experimental and control groups, meaning that while females did better overall, they didn't improve more or less than males.

As shown in Figure 2, there is variance in how much the players play each of the games. Similar variation is seen in the levels within the games that each student achieves (each of the games was divided into discrete units, and the number of these completed was collected). If the games increased understanding of the topics, we would expect to see a correlation between the time spent playing the game and the level of understanding as measured on the test. A multiple regression was conducted predicting score on each of the subtests by time spent playing the associated game and the level achieved in that game simultaneously. Table 4 shows the coefficient estimates for each of the associated factors in the model for models where there was a 
statistically significant effect. An x indicates that there was no statistically significant correlation.

Two games, Beetle Breeders (genetics) (overall model p=.026) and Island Hoppers (evolution) (overall model $\mathrm{p}<.01$ ) demonstrated (for a fixed time spent playing) a positive correlation between level of achievement and test score, meaning that students who got further in the game for a given amount of time demonstrated better content knowledge on their content assessment. Likewise, (for a fixed level of achievement) there was a negative correlation with respect to time, meaning that for students who achieved a particular level, getting there in less time meant scoring better on the tests. The assumption is that students who grasped the concepts were in fact able to achieve higher levels in the game and did so in a shorter period of time. One cannot say that the games were causative in this regard, but it does mean that performance in the games is a good indicator of understanding. As the player progresses in these games, he likely gains knowledge and insights into strategies that can help him (e.g., having read through more of the fact cards in Island Hoppers, or becoming familiar with the beetles' traits). For Invasion of the Beasties (overall model p=.047), test scores only showed a positive correlation with time spent playing the game, meaning students who played longer achieved higher test scores. It is worth noting, that Invasion of the Beasties requires students to use ingame reference materials (modeled on the Universal Genetic Code tables typically found in standard biology texts) and therefore players need to shift between screens to proceed through the games. The other games do not require such actions. Therefore it is also reasonable to assume that students who take the time to accurately look for the correct DNA sequences in fact grasp the concept more clearly. In other words, taking more time is necessary and a smart strategy to do well in this game. Chomp! showed no correlation with either time spent playing or 
with level of achievement. None of the games showed any significant interaction term for time spent playing and level achieved.

\section{Conclusions}

Despite numerous challenges faced by educators seeking to utilize game-based curriculum (Baek, 2008), games designed to overcome these barriers can be integrated into school curricula. The UbiqGames model, which leverages the portability of mobile computers, enabled access to the games outside of class time, freeing teachers to utilize class time for discussion of gameplay. However, the authors are aware of no existing research exploring a similar casual learning games model in formal educational settings or identifying design attributes (simulation-based or otherwise) specific to casual games which might promote student engagement and learning.

Despite data suggesting that female students on average spend substantially less time playing video games (Rideout et al., 2010), the UbiqBio games were able to engage both male and female players, possibly at least in part due to the fact that males and females already have roughly equivalent play patterns with respect to games played on smart phones. However, since the inherent appeal of biology to female players may have been a factor, it would be interesting to measure gender differences in engagement utilizing Ubiq-style games in other content domains (e.g., in which females do not tend to begin with strong interest).

The UbiqBio games were initially designed such that their content depth was roughly proportional to their topic's emphasis within the typical curriculum. However, as game designers, there was still a considerable amount of deliberation regarding how much domainspecific content to include in each game. We considered whether there would be more or less knowledge gains across more substantial, richer games. While deeper games might offer students 
more robust learning opportunities and sustain longer game play, they might also lose their novelty effect. Data suggests that a game with more content depth (Beetle Breeders) which was played roughly four times as much (in average minutes played) was generally more effective as a learning tool and may have motivated students to delve deeper in order to advance in the game. In addition to Beetle Breeders being the most deeply comprehensive game, it also had the greatest degree of variable difficulty. This is consistent with other research which found that “playability” factors (e.g., challenge) correlated highly with players' long term engagement with games (Febretti, \& Garzotto, 2009). This may explain why this game showed differences between the control and experimental groups' content assessment scores on this subtopic. It also suggests why progressing to higher levels correlates with test scores, allowing students to progress within their ZDP (Vygotsky, 1978). Conversely, more focused "practice" games which review procedures (e.g., reading a food web) but which do not provide as much depth may not be as "sticky" nor as impactful as more conceptual games. The level design of Chomp! was also relatively flat, lacking Malone's (1981) notion of appropriate levels of challenge, meaning it did not substantially progress in difficulty. This is consistent with a lack of difference between experimental and control groups' food web post-test scores, and the fact that neither time nor level are correlated with test scores. From the teacher's perspective, this difference between game types and the way performance is reflected in data is particularly relevant as games become more tightly integrated with classwork. For educators to adopt these games, they would like to not only trust that the games are engaging and effective, but also be able to utilize game data to assess students' content mastery. More comprehensive games which provide more nuanced feedback (like Beetle Breeders) better meet these teachers' needs, giving them an additional window into their students' abilities and knowledge within a particular subject matter. 
Given the correlations (and lack of correlations) between time spent playing, level achieved, and score on subtest, we might takeaway a number of lessons learned. In games covering difficult concepts where practice over time provides students repeated deliberate practice (Ericsson et al., 1993), we might expect games that employ repeated practice to yield reasonable results (as was the case in Invasion of the Beasties). Using that example, the levels within the game only grew slightly more complex over time. However the concept of translation - an inherently difficult one (Fisher, 1985) - may have become clearer to students over time as a result of repeated interaction and manipulation of game objects (which provided immediate simulation feedback).

In other games/subjects where concepts do get more difficult over time, both time spent and level achieved ultimately correlate with success in class. Early success in the game triggers more difficult concepts that extend their learning. This was the case for Beetle Breeders (genetics) where players delve deeper, spending more time and more effort to ultimately engage more deeply with the content.

Similarly in games/subjects covering a complex concept (like Island Hoppers/evolution), while the game does not substantially increase in difficulty, it does offer multiple distinct "puzzles" which give students opportunities to tease out the interrelationships at the heart of evolutionary selection pressures. As students played multiple times across repeated "missions," they had opportunities to test their understanding under different conditions. In this way, while the game itself did not get substantially harder, it featured a wider array of interrelated concepts that, with repeated exposure, may have helped solidify understanding.

Finally, in an all or nothing context, where students encounter a relatively simple concept that they either grasp quickly or seem to struggle with for a long time, games may not help much 
at all. This was the case for food webs (Chomp!). Students did not seem to get better over time or by level. This seems to be a representational issue about food webs that confuses some students (Barman, Griffiths, \& Okebukola, 1995) and may be better handled elsewhere. Chomp! however also lacked substantial wrong answer feedback, potentially another factor (Malone, 1981) in its inability to substantially improve learning outcomes. Furthermore, the lack of increasing levels of difficulty may have resulted in boredom (Chanel, Rebetez, Bétrancourt, \& Pun, 2008).

These principles are merely the beginning of a substantial body of research needed to better understand the potential and limitations of casual learning games within school contexts. However, these findings help inform designers as to which topics are well suited to games (e.g., topics where concepts build over time). This can help designers choose appropriate topics, but it can also help practitioners choose the domains and games where they are most likely to see learning gains, and therefore more open to utilizing a game-based approach. We hope this field of research expands to further examine what models of implementation and which particular qualities of learning games are likely to engage students and support a broad range of learners within the ecology of school. 


\section{References}

Baek, Y. K. (2008). What hinders teachers in using computer and video games in the classroom? Exploring factors inhibiting the uptake of computer and video games. Cyberpsychology \& Behavior, 11(6), 665-671.

Baker, J. W. (2000). The 'classroom flip': Using web course management tools to become the guide by the side; Selected Papers from the 11th International Conference on College Teaching and Learning (11th, Jacksonville, Florida, April 12-15, 2000).

Barman, C. R., Griffiths, A. K., \& Okebukola, P. A. (1995). High school students' concepts regarding food chains and food webs: A multinational study. International Journal of Science Education, 17(6), 775-782.

Buckley, B., Gobert, J., Horwitz, P. \& Dwyer, L. (2010). Looking inside the black box- assessing model-based learning and inquiry in BioLogica ${ }^{\mathrm{TM}}$. International Journal of Learning Technology. 5(2), 166-190.

Chanel, G., Rebetez, C., Bétrancourt, M., \& Pun, T. (2008, October). Boredom, engagement and anxiety as indicators for adaptation to difficulty in games. In Proceedings of the 12th international conference on entertainment and media in the ubiquitous era (pp. 13-17). ACM.

Clark, D., Nelson, B., Sengupta, P., \& D’Angelo, C. (2009, October). Rethinking science learning through digital games and simulations: Genres, examples, and evidence. In Learning Science: Computer Games, Simulations, and Education Workshop Sponsored by the National Academy of Sciences, Washington, DC.

Dondlinger, M. J. (2007). Educational video game design: A review of the literature. Journal of Applied Educational Technology, 4(1), 21-31.

Ericsson, K. A., Krampe, R. T., \& Tesch-Römer, C. (1993). The role of deliberate practice in the acquisition of expert performance. Psychological Review, 100(3), 363.

Febretti, A., \& Garzotto, F. (2009, April). Usability, playability, and long-term engagement in computer games. In CHI'09 Extended Abstracts on Human Factors in Computing Systems (pp. 4063-4068). ACM.

Fisher, K. M. (1985). A misconception in biology: amino acids and translation. Journal of Research in Science Teaching, 22(1), 53-62.

Gee, J. (2003). What Video Games Have to Teach Us about Learning and Literacy. New York: Palgrave.

Groff, J., Howells, C., \& Cranmer, S. (2012). Console game-based pedagogy: A study of primary and secondary classroom learning through console video games. International Journal of Game-Based Learning (IJGBL), 2(2), 35-54. doi:10.4018/ijgbl.2012040103

Groff, J. \& Mouza, C. (2008). A framework for addressing challenges to classroom technology use. AACE Journal, 16(1), 21-46. Chesapeake, VA: AACE.

Herz, J. C. (1997). Joystick Nation: How Videogames Ate our Quarters, Won our Hearts, and Rewired our Minds. Little, Brown \& Co. Inc.

Hickey, D. T., Kindfield, A. C., Horwitz, P., \& Christie, M. A. T. (2003). Integrating curriculum, instruction, assessment, and evaluation in a technology-supported genetics learning environment. American Educational Research Journal, 40(2), 495-538.

Honey, M. \& Hilton, M. (Eds.). (2011). Learning Science Through Computer Games and Simulations. Washington, D.C: The National Academies Press.

Jamison, H. (1973). Lemonade Stand [computer software]. 
Juul, J. (2009). A Casual Revolution: Reinventing Video Games and their Players. Cambridge, MA: The MIT Press.

Kebritchi, M. (2010). Factors affecting teachers' adoption of educational computer games: A case study. British Journal of Educational Technology, 41(2), 256-270. doi: 10.1111/j.1467-8535.2008.00921.x

Klopfer, E. (2008). Augmented Learning: Research and Design of Mobile Educational Games. Cambridge, MA: MIT Press.

Klopfer, E., Sheldon, J., Perry, J. \& Chen, V. H. (2012). Ubiquitous games for learning (UbiqGames): Weatherlings, a worked example. Journal of Computer Assisted Learning, 28(5), 465-476. doi: 10.1111/j.1365-2729.2011.00456.x

Lenhart, A. (2008). Teens, video games and civics: What the research is telling us. Pew Internet \& American Life Project, November 2, 2008, http://pewinternet.org/Presentations/2008/Teens-Video-Games-and-Civics.aspx, accessed October 1, 2012.

Lenhart, A. (2012). Teens, smartphones and texting. Pew Internet \& American Life Project, March 19, 2012, http://pewinternet.org/ /media//Files/Reports/2012/PIP_Teens_Smartphones_and_Textin g.pdf, accessed October 1, 2012.

Linn, M. (2005/2012). The knowledge integration perspective on learning and instruction. In Sawyer, R. K. (Ed.), The Cambridge Handbook of the Learning Sciences (pp. 243-264). Cambridge University Press.

Malone, T. W. (1981). Toward a theory of intrinsically motivating instruction. Cognitive Science, 5(4), 333-369.

Next Generation Science Standards. (2013). Retrieved from http://www.nextgenscience.org Odell Lake [computer software]. (1986). MECC.

Palmagotchi [computer software]. (2004). Cambridge, MA: MIT Scheller Teacher Education Program.

Papert, S. (1988). Does easy do it? Children, games, and learning. Game developer magazine.

Perry, J. \& Rosenheck, L. (2012). UbiqBio: A playful approach to learning biology with mobile games. Paper presented at the ISTE (International Society for Technology in Education), San Diego, CA.

Rawitsch, D., Heinneman, B. \& Dillenburger, P. (1971). The Oregon Trail [computer software]. MECC.

Rideout, V., Foehr, U. \& Roberts, D. (2010). Generation M2: Media in the lives of 8-18 year olds. Henry J. Kaiser Family Foundation Study. http://www.kff.org/entmedia/upload/8010.pdf, accessed 8 April, 2013.

Rosenheck, L. (2012). Beetles, beasties, and bunnies: Ubiquitous games for biology. In Dikkers, S., Martin, J., \& Coulter, B. (Eds.), Mobile Media Learning: Amazing Uses of Mobile Devices for Learning (pp. 77-96). Pittsburg, PA: ETC Press.

Salen, K. (2007). Toward an ecology of gaming. The ecology of games: Connecting youth, games, and learning, 1-17.

Sandford, R., Ulicsak, M., Facer, K. \& Rudd, T. (2006). Teaching with Games: final report. Futurelab, UK 
http://futurelab.org.uk/resources/documents/project_reports/teaching_with_games/TWG_ report.pdf

Shaffer, D. W., Squire, K. D., Halverson, R., \& Gee, J. P. (2005). Video games and the future of learning. Phi Delta Kappan, 87(2), 104-111.

Squire, K. D. (2003). Video games in education. Int. J. Intell. Games \& Simulation, 2(1), 49-62.

Squire, K. D., \& Barab, S. A. (2004). Replaying history: Learning world history through playing Civilization III. Bloomington: Indiana University.

Steinkuehler, C. A. (2006). Massively multiplayer online video gaming as participation in a discourse. Mind, Culture, and Activity, 13(1), 38-52.

Thiagarajan, S. (1999). The myths and realities of simulations in performance technology. Educational Technology, 38(5), 35-41.

Vygotsky, L. (1978). Mind in Society.

Weatherlings [computer software]. (2009). Cambridge, MA: MIT Scheller Teacher Education Program.

Weinburgh, M. H., \& Englehard, G. (1994). Gender, prior academic performance and beliefs as predictors of attitudes toward biology laboratory experiences. School Science and Mathematics, 94(3), 118-123.

Wright, W. (1989). SimCity [computer software]. Orinda, CA: Maxis. 


\section{Tables}

Table 1. Design features counteracting factors inhibiting teachers using games in schools.

\begin{tabular}{ll}
\hline Barrier & UbiqGames' \& UbiqGames' Curriculum Design Feature \\
\hline Inflexibility of Curriculum & $\begin{array}{l}\text { All games and related curricular materials are closely linked to } \\
\text { content standards }\end{array}$ \\
\hline Negative Effects of Gaming & Games are not explicitly hyper-competitive \\
\hline Students' Lack of Readiness & Games utilize 'casual' style, with short learning curve \\
\hline Lack of Supporting Materials & $\begin{array}{l}\text { Integrated curricular materials provide teachers with framework } \\
\text { including suggested discussion points, worksheets, and activities } \\
\text { linked to gameplay; Teacher portal supports teachers' awareness of } \\
\text { students' game activities }\end{array}$ \\
\hline Fixed Class Schedules & $\begin{array}{l}\text { Playable on most browsers, and optimized for mobile devices, } \\
\text { gameplay takes place primarily outside of class time, allowing } \\
\text { teachers to utilize class for facilitated discussion/reflection }\end{array}$ \\
\hline Limited Budgets & $\begin{array}{l}\text { UbiqGames and related curriculum are available to educators and } \\
\text { students at no cost }\end{array}$ \\
\hline
\end{tabular}


Table 2. Summary UbiqBio games' Design attributes

\begin{tabular}{lllllll}
\hline Game & $\begin{array}{l}\text { Subject } \\
\text { Matter }\end{array}$ & $\begin{array}{l}\text { Simulation } \\
\text { Feedback }\end{array}$ & $\begin{array}{l}\text { Content } \\
\text { Depth }\end{array}$ & $\begin{array}{l}\text { Narrative } \\
\text { Realism }\end{array}$ & $\begin{array}{l}\text { Variable } \\
\text { Difficulty }\end{array}$ & $\begin{array}{c}\text { Type of } \\
\text { Knowledge }\end{array}$ \\
\hline $\begin{array}{l}\text { Beetle } \\
\text { Breeders }\end{array}$ & $\begin{array}{l}\text { Classical } \\
\text { genetics } \\
\text { (Punnett } \\
\text { squares, } \\
\text { dominance, } \\
\text { patterns of } \\
\text { inheritance) }\end{array}$ & moderate & extensive & realistic & extensive & conceptual \\
& & & & \\
& & & & & \\
\hline $\begin{array}{l}\text { Invasion } \\
\text { of the } \\
\text { Beasties }\end{array}$ & $\begin{array}{l}\text { Protein } \\
\text { Synthesis } \\
\text { (DNA } \\
\text { translation) }\end{array}$ & extensive & moderate & metaphor & moderate & procedural \\
\hline $\begin{array}{l}\text { Island } \\
\text { Hoppers }\end{array}$ & $\begin{array}{l}\text { Evolution } \\
\text { (population } \\
\text { distributions, } \\
\text { selection } \\
\text { pressures) }\end{array}$ & & & & & \\
& & & & & \\
& & & & & & \\
\hline Chomp! & $\begin{array}{l}\text { Food Webs, } \\
\text { energy } \\
\text { transfer }\end{array}$ & minimal & focused & metaphor & flat & procedural \\
& & & & & \\
\hline
\end{tabular}


Table 3. Typical curriculum for UbiqBio game, e.g., Invasion of the Beasties.

\begin{tabular}{|c|c|c|}
\hline Day & Curriculum & Materials \\
\hline 1 & Discuss transcription & $\begin{array}{l}\text { Invasion of the Beasties - Worksheet } 1 \text { - } \\
\text { practicing complimentary base pairing rules } \\
\text { transcribing DNA to mRNA }\end{array}$ \\
\hline 2 & Discuss Translation & $\begin{array}{l}\text { Invasion of the Beasties - Worksheet 2- } \\
\text { practicing complementary base pairing rules } \\
\text { mRNA to tRNA } \\
\text { Work with genetic code to match codons to } \\
\text { amino acids }\end{array}$ \\
\hline 3 & $\begin{array}{l}\text { Introduce game. "Imagine that you are able } \\
\text { to create monsters by genetically } \\
\text { engineering them while they are still } \\
\text { zygotes. Your monsters are being attacked } \\
\text { by vicious beasties. These beasties all have } \\
\text { different characteristics that make them } \\
\text { easier or harder to defeat. You have to } \\
\text { genetically engineer your monsters with } \\
\text { traits that will make it easier for them to } \\
\text { defeat the beasties. Using your knowledge of } \\
\text { the genetic code and translation, you are } \\
\text { going to match tRNA anticodons to the } \\
\text { appropriate mRNA codons to bring the } \\
\text { amino acids into the correct sequence to } \\
\text { make the proteins that will make your } \\
\text { monster able to defeat the attacking beastie." }\end{array}$ & $\begin{array}{l}\text { Worksheet 3- Concept Review sheet } \\
\text { clarifying vocabulary with examples. }\end{array}$ \\
\hline 4 & $\begin{array}{l}\text { Review process of translation. Discuss game } \\
\text { play. Discussion Questions: In level one, } \\
\text { how did you engineer your monster to have } \\
\text { the desired traits? In level two, how did you } \\
\text { engineer your monster to have the desired } \\
\text { traits? In level three, was there only one } \\
\text { codon that coded for each amino acid? }\end{array}$ & Worksheet 4- Game-like questions. \\
\hline 5 & $\begin{array}{l}\text { Translation Activity-Paper Lab- Students } \\
\text { will match tRNA anticodons to mRNA } \\
\text { codons and create sequences of amino acids. } \\
\text { They will also look at how changes in the } \\
\text { mRNA sequence can change the amino acid } \\
\text { sequence. }\end{array}$ & $\begin{array}{l}\text { Optional article, "Gene Pool" about genetic } \\
\text { engineering for in-class discussion. }\end{array}$ \\
\hline
\end{tabular}


Table 4. Coefficient Estimates for Play Time and Level Achieved on Test Score Per Game

\begin{tabular}{llll}
$\begin{array}{l}\text { Beetle } \\
\text { Breeders } \\
\text { (Genetics) }\end{array}$ & $\begin{array}{l}\text { Beasties (DNA } \\
\text { Translation) }\end{array}$ & $\begin{array}{l}\text { Island Hoppers } \\
\text { (Evolution) }\end{array}$ & $\begin{array}{l}\text { Chomp! } \\
\text { (Food Webs) }\end{array}$ \\
\hline
\end{tabular}

\begin{tabular}{lllll}
\hline Time $(10 \mathrm{~K})$ & $-.039^{* *}$ & $.0647^{* *}$ & $-.223^{* *}$ & $\mathrm{x}$ \\
\hline Level & $.245^{* *}$ & $\mathrm{x}$ & $.0138^{* *}$ & $\mathrm{x}$ \\
\hline
\end{tabular}

Table 4. Table showing the coefficient estimates for time spent playing and level achieved on test score for each of the games/topics. All models shown are statistically significant ( $\mathrm{p}<.05)$. An $\mathrm{x}$ indicates no statistically significant influence of that coefficient for that model. 
Figures
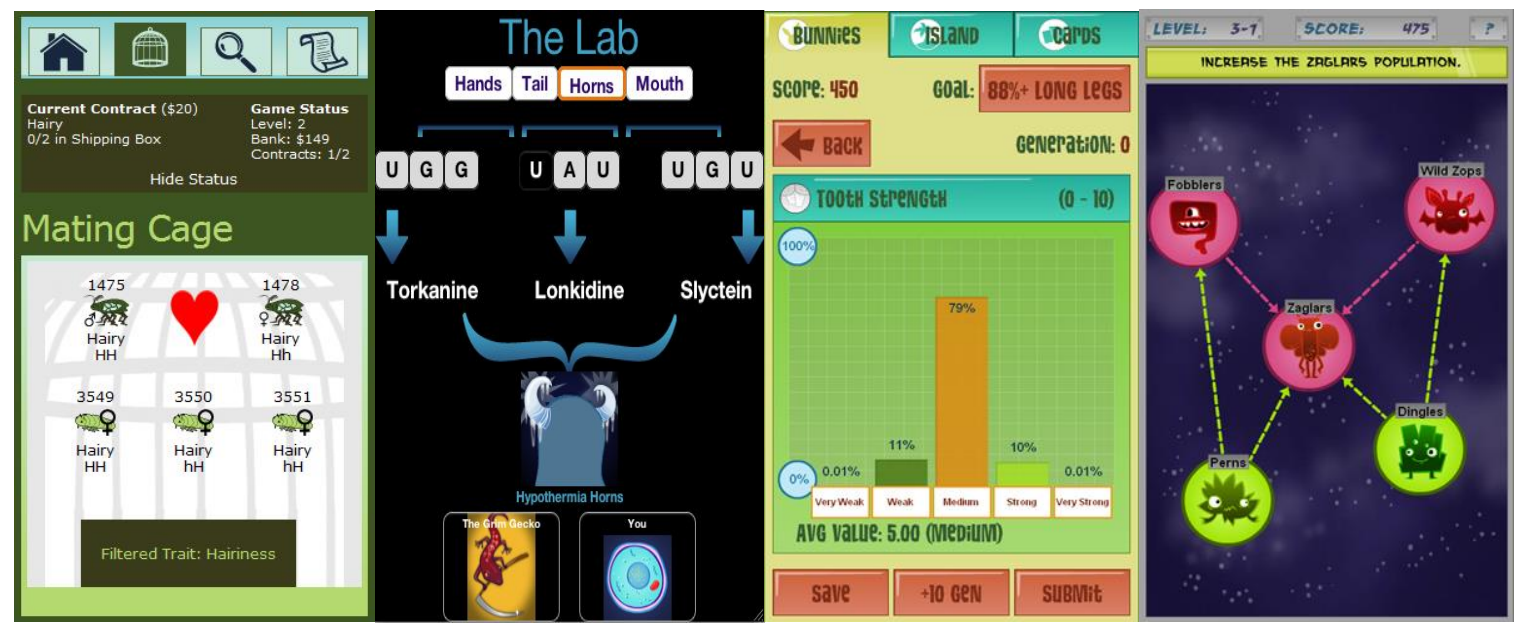

Figure 1. Screen shots (left to right) from the UbiqBio games: Beetle Breeders, Invasion of the Beasties, Island Hoppers and Chomp! 


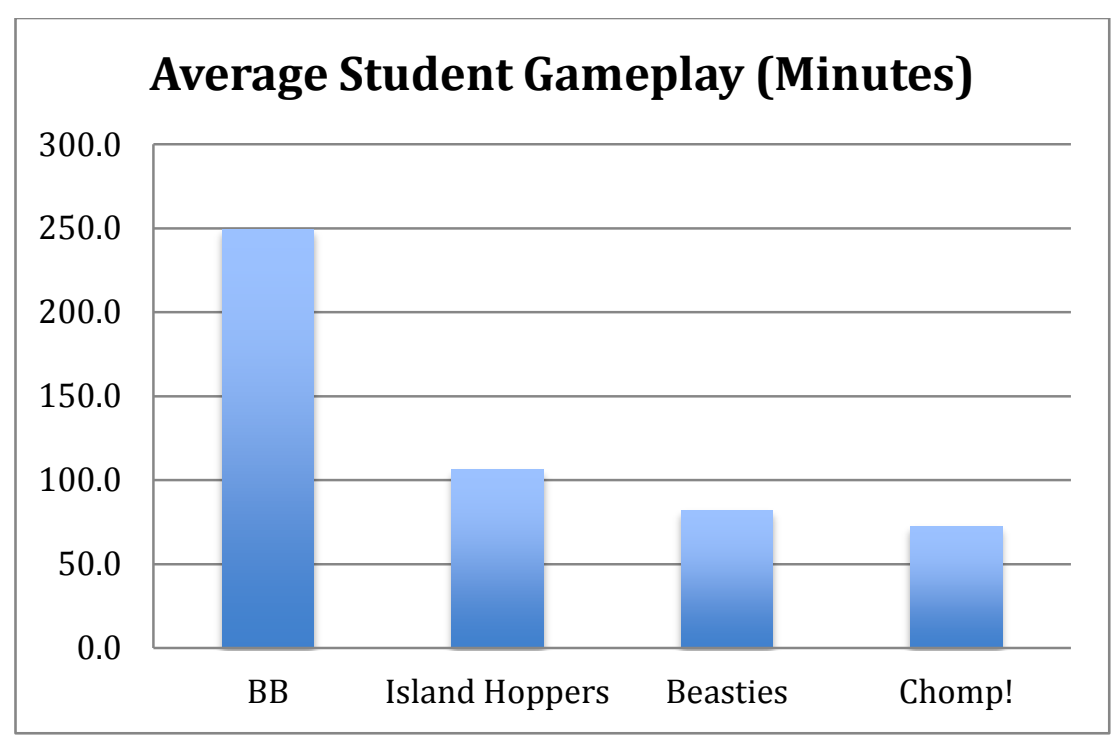

Figure 2. Graph of average number of minutes played per game. 


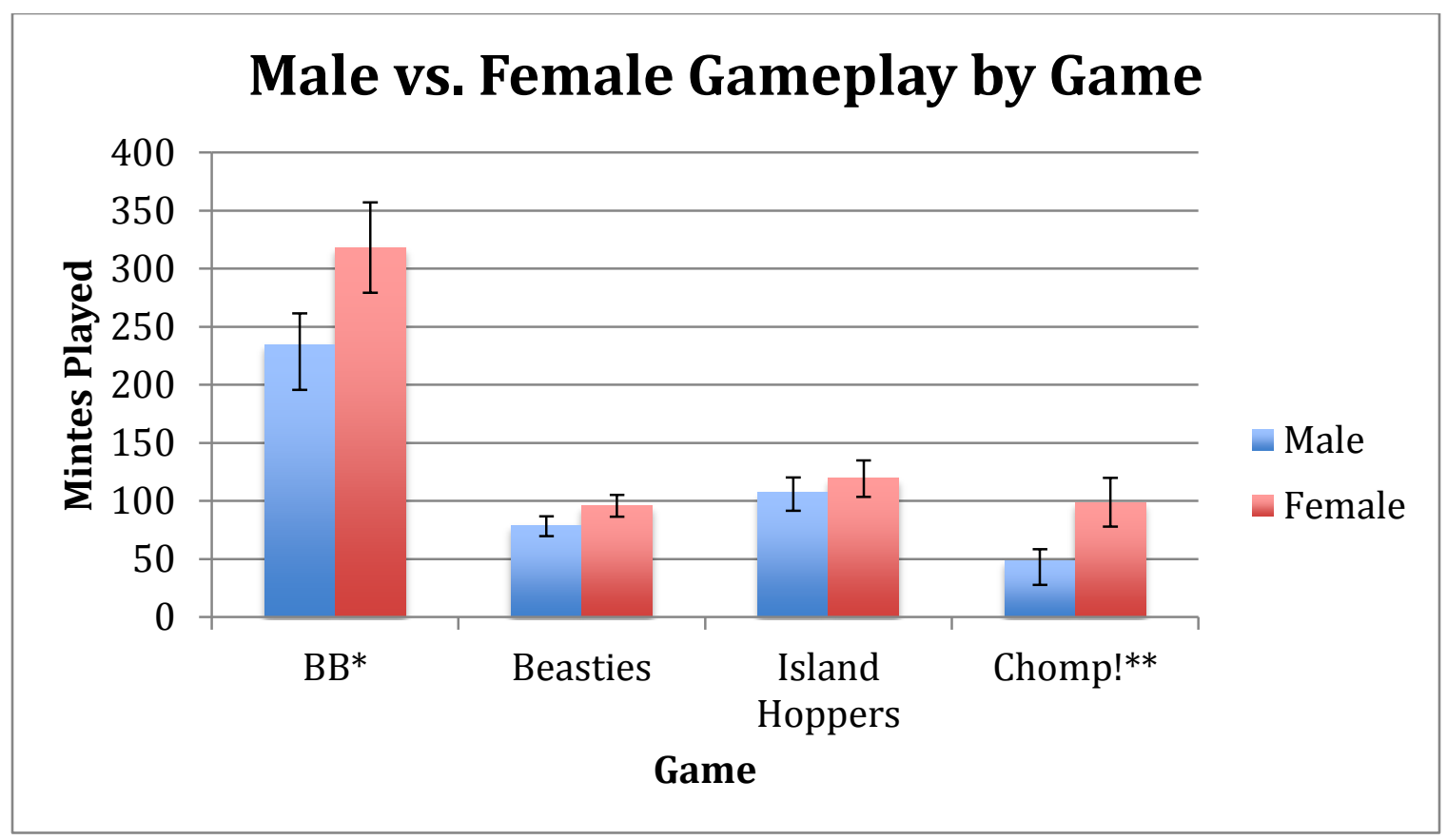

Figure 3. Graph showing male versus female time played per game in minutes. Bars represent standard error of the mean. Chomp! showed a statistically significant difference $(\mathrm{p}=.034)$, while Beetle Breeders (BB) did not show a statistically significant difference $(\mathrm{p}=.081)$. 


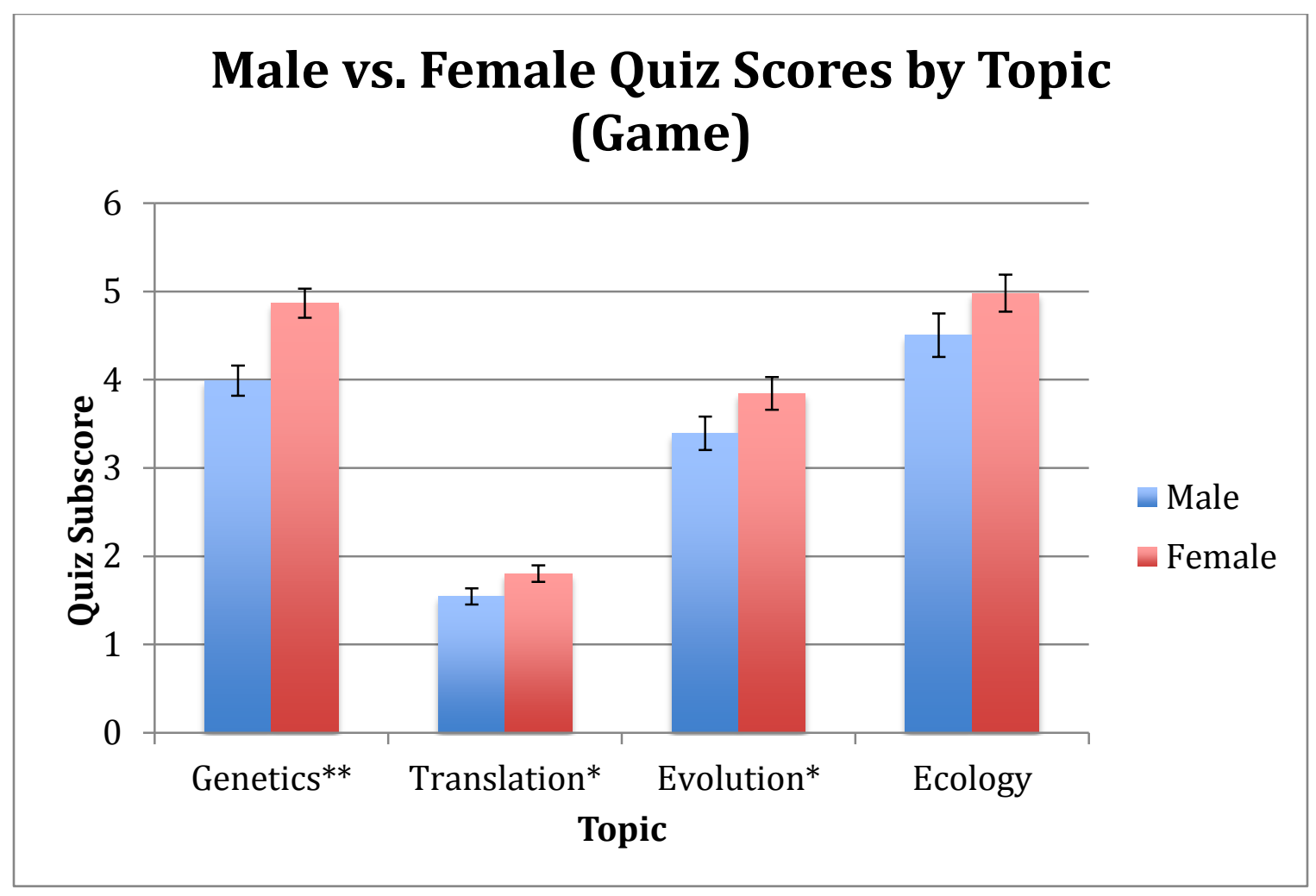

Figure 4. Graph showing male versus female score on assessment components. Bars represent standard error of the mean. Genetics shows a statistically significant advantage for females $(\mathrm{p}<.01)$, while the difference is not statistically significant for females in translation $(\mathrm{p}=.055)$, and evolution $(\mathrm{p}=.088)$. 


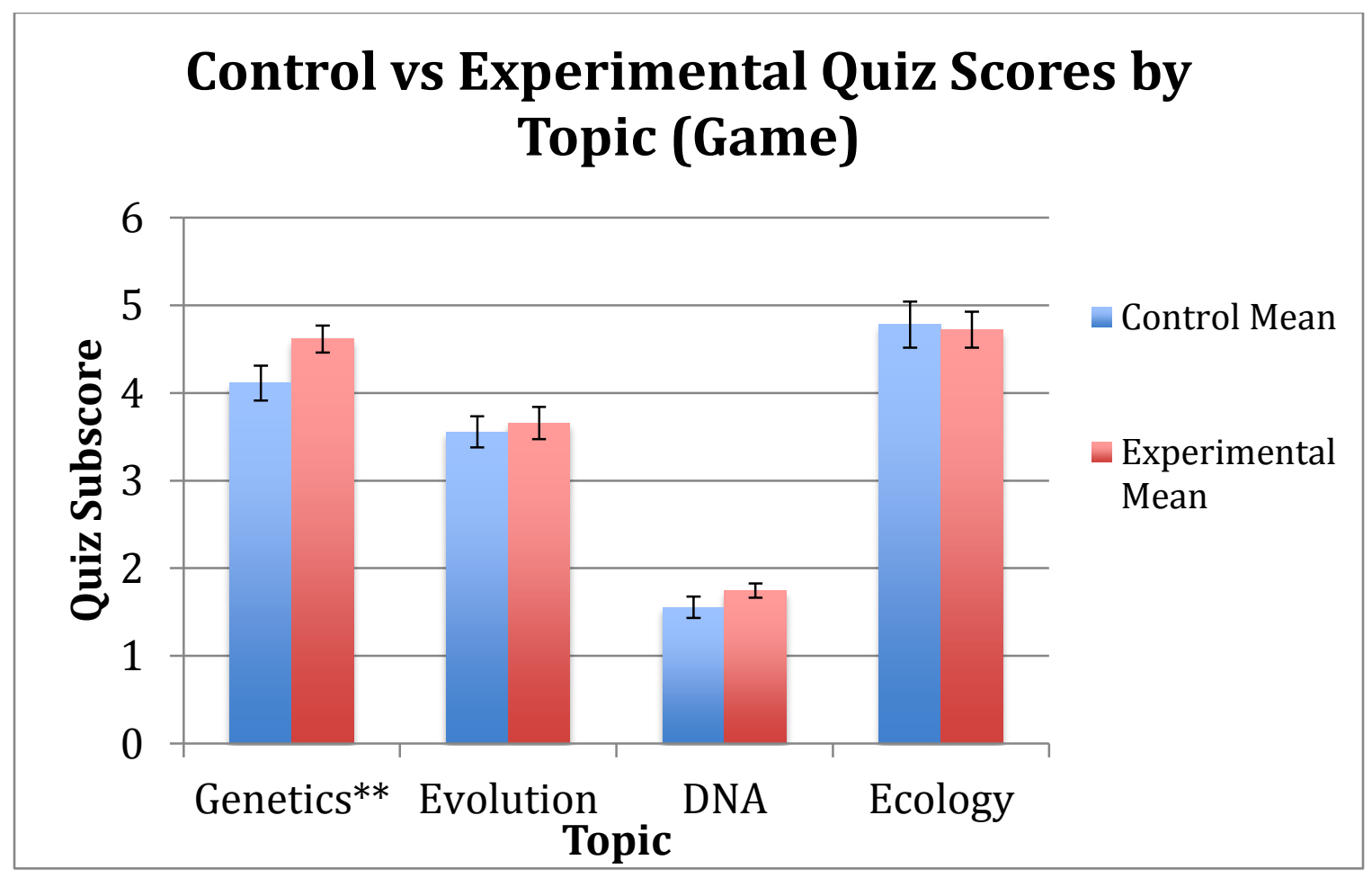

Figure 5. Graph comparing quiz scores by topic in control vs. experimental groups. Bars represent standard error of the mean. Only genetics shows a statistically significant difference between control and experimental groups $(\mathrm{p}=.0472)$. 